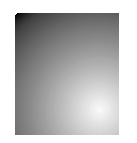

\title{
ReLAÇões Informais Influenciadas pela Estrutura FORMAL: UMA ANÁLISE DE REDES SOCIAIS DE GESTORES
}

\author{
Informal Relations Influenced by Formal Structure: a social \\ network analysis managers
}

\author{
Raquel de Nazaré Cota Conde \\ Mestre em Administração. Consultora da SBCoaching Empresas. Belém, PA. Brasil. E-mail: raquelcotaconde@gmail.com \\ Milton Cordeiro Farias Filho \\ Doutor em Desenvolvimento Socioambiental. Professor do Programa de Pós-Graduação em Administração da Universidade da \\ Amazônia - UNAMA. Belém, PA. Brasil. E-mail: mcffarias@gmail.com
}

\section{Resumo}

As organizações, como um sistema social, possuem duas estruturas de relações: formal e informal. Esse entendimento é a base da pesquisa aqui relatada e teve como objetivo identificar de que maneira a estrutura formal da organização influencia as relações informais entre gestores para troca de conhecimentos técnicos. As evidências vêm de duas empresas de varejo do estado do Pará. Utilizou-se o método de Análise de Redes Sociais (ARS), aplicou-se questionário semiaberto (gerador de nomes) com 59 gestores que foi complementado com duas entrevistas livres realizadas com gerentes de $\mathrm{RH}$. Os resultados, analisados a partir do software Ucinet 6.2/Netdraw 2.0, indicam que gestores buscam conhecimentos técnicos em suas redes de relacionamentos (formal e informal) e que tais redes auxiliam nos resultados organizacionais. Concluiu-se que as relações informais induzem a melhoria de processos e auxiliam os gestores na superação de barreiras da estrutura formal e na difusão de conhecimentos na organização.

Palauras-chave: Relações. Formal. Informal. Gestores. Recursos.

\section{Abstract}

Organizations are social system due to this they have two structures that people relate through: formal and informal. This concept is the basis of the research reported in this essay, which aimed to identify how the formal structure of the organization influences the informal relationships between managers to exchange expertise. The evidence comes from two retail companies in the state of Pará. We used the method of Social Network Analysis (SNA) with a semiopen questionnaire (name generator) answered by 59 managers and complemented with two free interviews with HR managers. Data was analyzed trough Ucinet 6.2/2.0 software Netdraw, they indicate that managers seek technical knowledge in their social networks (formal and informal) and these help organizational results. We conclude that informal relations induce process improvement and help managers to overcome barriers of formal structure and disseminate knowledge in the organization.

Keywords: Relations. Formal. Informal. Managers. Resources. 


\section{INTRODUÇÃo}

As organizações estabelecem como as relações formais devem ser conduzidas em seu interior e essas interações são graficamente estruturadas nos organogramas. No entanto, as pessoas mantêm relacionamentos informais, além dessa estrutura formal, em que trocam conhecimentos, informações, influência, etc. Essa informalidade é derivada das relações sociais na organização e são espontâneas e casuais; enquanto as relações formais são cerimoniais e previstas em normas e procedimentos.

É a estrutura formal que regula o fluxo de energia para atingir objetivos (MACDONALD; BURKE; STWART, 2006). Porém, o estudo da hierarquia, com suas divisões funcionais das atividades, tem uma compreensão mais ampla quando associado com a análise das redes sociais, que são relações complexas de vínculo entre atores em um sistema social (REQUENA SANTOS, 1989), formadas pelas interações informais entre eles. A forma mais comum para explicação de uma rede social é a representação gráfica de suas relações, conhecida como sociograma (MOLINA, 2000).

As organizações reconhecem as relações informais e algumas passaram a incluir relações horizontais nos organogramas. Daft (2008) argumenta que mesmo que as conexões horizontais não estejam desenhadas no organograma, elas fazem parte da estrura organizacional. Para tanto, Molina (2000) afirma não ser possível entender a estrura formal dissociada da informal. Por sua vez, Garcia (2012) alerta para a possibilidade da perda de competividade, caso as relações informais sejam desconsideradas, porque nelas circulam informações e outros recursos intangíveis importantes para a competição por exemplo, o conhecimento técnico).

Contudo, o alinhamento entre as duas perspectivas (formal e informal) não acontece por acaso. É necessária a integração de forma aberta e sistemática para que se obtenham melhores resultados para a organização (CROSS; PRUSAK, 2002). Diante deste contexto, a pesquisa relatada neste artigo buscou resposta para a seguinte questão: de que maneira a estrutura formal da organização influencia as relações informais entre gestores para troca de conhecimentos técnicos? Para responder a esta pergunta foi necessário verificar como as pessoas interagem para obter informações $e$ conhecimentos que ajudem a melhorar seus processos de trabalho e verificar as formas como as informações são trocadas entre os indivíduos.

Um levantamento bibliográfico em bases de textos nacionais e internacionais, com uso das palavras-chave "análise de redes sociais"; "redes em organizações"; "estruturas formais e informais", revelou a existência de poucos trabalhos na literatura nacional sobre fenômenos relacionais em organizações. Portanto, a pesquisa busca contribuir com o que Zancan, Santos e Campos (2011) sugerem como necessidade de mais estudos com uso da análise de redes sociais (ARS) em estudos organizacionais.

Assim, o objetivo do estudo foi identificar de que maneira a estrutura formal da organização influencia as relações informais entre gestores para troca de conhecimentos técnicos. Para isso foi realizado um survey com uso de questionário online na plataforma Google Docs. Este foi respondido por 59 gestores (gerentes e supervisores) de duas empresas (matriz e filiais) do segmento de varejo do estado do Pará. Os dados foram analisados com uso do software específico para análise de redes sociais (Ucinet 6.2/Netdraw 2.0). Após as análises, foram realizadas entrevistas com cada gerente de recursos humanos das duas empresas para complementação das análises e verificação de consistência e coerência dos dados gerados no survey.

Os resultados mostram que gestores buscam conhecimentos técnicos em suas redes de relações informais e que estas são induzidas pela estrutura formal da organização. Para os gestores a implantação de melhorias na organização em que atuam é resultado da interação social e funcional e de como os recursos (especialmente o conhecimento) estão distribuídos. A conclusão é de que as relações informais trazem agilidade aos processos e ajudam superar as barreiras impostas pela estrutura formal e que a hierarquia funcional não é fonte exclusiva para difusão do conhecimento na organização.

\section{O Conhecimento como Recurso}

A circulação do conhecimento nas organizações tem potencial para favorecer a melhoria de processos internos. O uso e a aplicação do conhecimento como um recurso vai depender da forma, velocidade e intensidade de como ele circula em uma rede. 
Pierce e White (1999) desenvolveram a teoria socioevolucionária para mostrar que é o contexto dos recursos que define a formação social mais adequada. Quando o recurso está concentrado, sua localização é previsível. É possível então verificar seu uso, porém esse uso não é imediato. Uma estrutura hierarquizada é estabelecida para realizar a distribuição desse recurso e evitar a quebra da estrutura social na organização. Em ambientes de recursos dispersos, com localização imprevisível, de difícil visualização, o consumo precisa ser imediato; o grupo precisa se dispersar para sua obtenção, tornando a coesão mais fraca. Nesse segundo caso, para não haver a quebra da estrutura social, os membros do grupo investem em relacionamentos.

De acordo com a teoria socioevolucionária, recursos concentrados demandarão uma estrutura hierárquica formal, que se assemelham aos sistemas mecanicistas da teoria das contingências. Já o ambiente de recursos dispersos criam estruturas sociais similares aos sistemas orgânicos dessa teoria.

Diante de um ambiente de economia sustentada em conhecimento (DRUCKER, 1995), ainda existem organizações com funcionamento baseado na visão mecanicista (DAFT, 2008), porque são as divergências que impulsionam estudos organizacionais (REED, 1998) e não o consenso.

O conhecimento técnico, como um recurso intangível nas organizações, circula não apenas nas trocas formais, mas também nas redes sociais informais que são geradas pelas relações de rotinas entre pessoas. Gerentes são capazes de identificar gaps de fluxo de informações e combinar recursos adequadamente, se eles entendem como funcionam as redes sociais de sua organização (CROSS; BORGATTI; PARKER, 2002).

O interesse pela compreensão do funcionamento das redes sociais informais nas organizações e o seu impacto na estrutura formal crescem, com maiores entendimentos sobre a interação entre as preferências individuais e as oportunidades seletivas (KLEINBAUM; STUART; TUSHMAN, 2013), porque os processos e a tomada de decisão são influenciados pelos papéis informais (DE TONI; NONINO, 2010). Dessa forma, as relações sociais nas organizações são orientadas pela concentração ou dispersão dos recursos entre atores organizacionais.

\section{Estrutura e Design Organizacional:}

\section{A PERSPECTIVA FORMAL}

A estrutura de uma organização pode ser considerada como ambiente de relacionamentos rotineiros existentes entre pessoas (DONALDSON, 1988), levando cada uma a ter suas relações nessa estrutura condicionadas pelas tarefas, ambiente ou estratégia (DRUCKER, 2001). O organograma mostra a estrutura básica, ele pode estar definido por funções, divisões, geografia ou ter uma composição híbrida (CUNLIFFE, 2008; DAFT, 2008).

A formalização está relacionada à quantidade de documentos escritos (DAFT, 2008), como procedimentos, normas, descrições de cargos, comunicação escrita. O excesso de formalização pode ser problemático para organizações que estejam em ambientes que requeiram flexibilidade e respostas mais rápidas às mudanças ambientais (CUNLIFFE, 2008).

A centralização e descentralização estão relacionadas com o nível em que as decisões são tomadas $e$ onde os recursos são alocados. A centralização impõe mais controle e efetividade no uso dos recursos (CUNLIFFE, 2008) e ainda pode ser usada por um gerente para impedir que alguém lhe faça "sombra" (OLIVEIRA, 2006). Já a descentralização propõe maior autonomia e conduz criatividade, inovação, flexibilidade e motivação.

As estruturas das organizações, elaboradas com base no nível de complexidade da função e da tarefa a ser desempenhada (LEE, 2007), incluem as relações de interdependência, tendo como sua melhor forma de aproximação o organograma, porém ele nem sempre é preciso e, em algumas vezes, é ambíguo (NELSON, 1984).

A organização hierárquica estabelecida no organograma define também a linha de autoridade e comunicação. No entanto, os problemas de comunicação são mais frequentes em estruturas com maior número de níveis (MANDELLI, 2010). Para que a estrutura funcione, ela precisa de planejamento que deixe claro o que é esperado de cada componente (MCDONALD; BURKE; STEWART, 2006).

O gerente é a pessoa que tem a responsabilidade pelo resultado do trabalho de uma equipe, além de ter que responder pelo seu próprio desempenho. Espera-se que ele esteja sempre informado sobre sua área de 
responsabilidade e centralize demandas, que se tornam centrais na estrutura.

Como na estrutura formal a previsibilidade é crítica, espera-se do gerente que ele tome decisões com base na autoridade que lhe foi delegada para que atinja os objetivos estabelecidos (MACDONALD; BURKE; STEWART, 2006). Se por um lado a estrutura dá confiabilidade e conforto ao sistema; por outro, ela não dá espaço para inovar (MORGAN, 2002). No contexto formal, as pessoas sentem maior dificuldade na comunicação, o que se agrava com o aumento de níveis hierárquicos (MANDELLI, 2010), ao mesmo tempo em que experimentam senso de pertencimento.

Com a técnica e a tarefa mais valorizadas, a equipe fica alienada, o que pode baixar o desempenho, sem que o gerente perceba que a falta de empenho é em função da alienação (MANDELLI, 2010). Isso pode mostrar a não percepção de outra variável para o desempenho: a estrutura informal da organização. Ela pode ser estratégica quando percebida e valorizada.

\section{A INFORMALIDADE: OUTRA FACE DA ORGANIZAÇÃO}

É inviável para uma organização depender apenas das relações formais estabelecidas, principalmente quando seu nível de complexidade é elevado, pelo crescimento, diversificação de produtos e mercados (NELSON; DE VASCONCELLOS, 2007) e quando precisam passar por mudanças (MORGAN, 2002).

Sendo socialmente construída, a estrutura informal existe na abstração $e$ as pessoas a impregnam com significado moral e mesmo que seja a rede informal quem determina como o trabalho é feito (GARCIA, 2012), organizações que sejam unicamente estabelecidas em relações informais apresentam disfunções na implantação e condução de estratégias (NELSON; DE VASCONCELLOS, 2007).

A informalidade é fundamental para as organizações, pois permite comunicação rápida é necessária (MORAND, 1995). De acordo com Moscovici (2003), é difícil uma pessoa ousar com formas criativas em ambientes de estrutura linear racional e lógica. Para buscar desempenho superior é importante encorajar a equipe a aumentar seu nível de sociabilidade. Assim, as pessoas passam a se conhecer além do ambiente formal do trabalho e podem perceber que cada uma tem virtudes e defeitos, qualidades e problemas (MANDELLI, 2010). Esse fato leva as pessoas a se agruparem a partir de suas relações que se formam em redes sociais.

Nas redes sociais de relações informais existe também a possibilidade de ajuda mútua (LAMERTZ, 1999) e de aprendizagem, que acontece, por exemplo, na integração de funcionários, na realização de tarefas diárias. Ela é mais experimental do que institucional e muitas vezes de difícil percepção, avaliação e mensuração (FLACH; ANTONELLO, 2010). No entanto, no ambiente organizacional a rede de relações informais é considerada como secundária, dada a importância atribuída à estrutura formal de relações. Drucker (2001) adverte que abrir mão da hierarquia (estrutura de relações formais) seria abrir mão da própria sobrevivência, principalmente em período de crise, quando se depende de um comando firme.

A estrutura organizacional formal e geográfica delimitam as oportunidades de interação, porém dentro das limitações de unidades de negócios e escritórios os atores têm liberdade para escolher os seus parceiros. Kleinbaum, Stuart e Tushman (2013) mostram ainda que as mulheres são mais propensas a romper os limites impostos, mesmo que buscando caminhos funcionais, porque buscam apoio social de outras pessoas; enquanto as redes de homens apresentam padrões consistentes com o efeito restritivo da unidade de negócios e escritório.

Estudos mais recentes vêm mostrando que em empresas de serviços financeiros a coerência entre as redes formal $e$ informal influenciam o desempenho (SODA; ZAHEER, 2012). Nessa mesma linha, Akhter, Siddique e Masum (2011) perceberam a melhoria do desempenho através de redes informais e foram além. Eles mostraram que isso é alcançado pela redução dos limites colocados pela estrutura funcional, resultando na melhoria da coordenação de atividades, o que contribui para a satisfação do empregado.

Essa melhoria no desempenho acontece porque é a estrutura de relações informais que tem a capacidade de combinar recursos e competências que são amplamente dispersos em toda a empresa, para a realização de tarefas complexas. Gulati e Silvestri (2013) utilizam o conceito de "região de brokerage" como um espaço onde as estruturas formal $e$ informal se sobrepõem para facilitar e apoiar a realização de tarefas complexas. 
A combinação dos recursos em algumas ocasiões é realizada por líderes informais, que foram denominados de pilus prior (DE TONI; NONINO, 2010). Esses líderes emergem do grupo e contribuem para o desempenho de seus colegas. Eles são capazes de sintetizar a resolução de problemas, os conhecimentos $e$ as características de acessibilidade. Para esses autores, mesmo em organizações onde não existe estrutura hierárquica formal, como em conselhos de administração, é possível perceber o impacto das estruturas informais.

A hierarquia informal influencia o desempenho financeiro da empresa e o entendimento dessa hierarquia gerada nos conselhos de administração tem potencial para melhorar a governança corporativa (HE; HUANG, 2011). O impacto da estrutura informal pode ser percebido mesmo em conselhos gestores que não possuem estrutura hierárquica formal baseada na deferência de um membro em relação ao outro.

\section{A Integração Formal-Informal}

As relações formais se caracterizam por seguirem normas, regras, políticas, procedimentos escritos da organização (CUNLIFFE, 2008) e por fazerem a "[...] distribuição das responsabilidades e autoridades pelas unidades organizacionais da empresa" (OLIVEIRA, 2006, p. 43). Soda e Zaheer (2012) entendem que o formal e informal se complementam ou suplementam, com implicações para o desempenho dos atores.

A ênfase na hierarquia (DAFT, 2008; DRUCKER, 2001) e a regulação, comando e controle (MINTZBERG, 1995) são facetas visíveis da estrutura formal nas organizações e a estrutura formal é percebida pela ajuda mútua entre os atores que levam aprendizagem (FLACH; ANTONELLO, 2010) e pela rapidez que oferece ao processo decisório (MORAND, 1995).

No contexto de relações entre as estruturas formal e informal nas organizações, o método de análise de redes sociais é bastante adequado para a percepção do fenômeno e de suas implicações, pois, como sustentam Zancan, Santos e Campos (2011), a utilização das medidas da análise de redes sociais (ARS) em abordagens organizacionais é fundamental para a compreensão de fenômenos relacionais.

A análise das relações pelas redes sociais permite identificar se as reações estão levando a uma estrutura mais coesa ou dispersa. Em uma estrutura coesa, a teoria socioevolucionária aponta para o conhecimento centralizado e estrutura dispersa para conhecimentos mais dispersos na organização.

\section{Método e Procedimentos}

Este estudo utilizou como variáveis centrais as informações e conhecimentos técnicos para busca de melhorias necessárias nas empresas. As questões de interação entre pessoas foram baseadas na análise de redes sociais, que permitiram mapear e quantificar a intensidade dos fluxos de comunicação e troca de conhecimentos. Tais procedimentos estão sustentados em duas suposições:

Suposição A: se informações e conhecimentos técnicos estão dispersos nas equipes de trabalho, as relações formais oriundas da hierarquia funcional das equipes não são fontes exclusivas de difusão dessas informações e conhecimentos.

Suposição B: se as relações informais nem sempre seguem a mesma lógica da estrutura formal da organização, então a difusão de informações e conhecimentos técnicos é favorecida pela interação das duas estruturas relacionais (formal e informal), porém a estrutura formal induz os relacionamentos informais.

Para verificação das suposições foram estudadas duas organizações empresariais do setor de varejo com sede em Belém-PA e filiais em outros municípios e estados do Norte e Nordeste do país. As empresas foram selecionadas por terem algumas semelhanças: liderança em suas áreas de atuação, tempo de existência, tamanho, localização e dispersão espacial.

A primeira empresa (Empresa 1) atua com lojas do tipo magazine e possui nível de formalização (processos escritos e documentados em manual) mais elevado que a segunda (Empresa 2). Esta atua na venda de equipamentos e serviços de informática, não dispõe de procedimentos escritos, nem de organograma, pois seus proprietários acreditam que as pessoas devem se comunicar de forma livre dentro da organização, de acordo com as necessidades do trabalho.

As empresas e seus informantes não foram identificados, seguindo a recomendação de Borgatti e Molina (2003). Seus nomes foram codificados nas ilustrações (sociogramas). A coleta de dados aconteceu mediante 
autorização das empresas, após orientação dada pelos pesquisadores aos participantes. Estes (gerentes e equipes) forneceram seus e-mails.

Os dados foram coletados em questionário eletrônico inserido na plataforma Google Docs e enviado por e-mail. Foram preenchidos 29 questionários na Empresa 1 e 30 na Empresa 2, representando quase o total dos gestores.

O questionário tinha três blocos. Bloco I: com questões sociodemográficas; Bloco II: com questões de análise de redes sociais, baseadas em interações, fluxo do conhecimento para realização de tarefas ou para gerar melhorias no trabalho (rede de trabalho); Bloco III: com perguntas sobre as ideais de melhoria apresentadas e implementadas (rede de troca de ideias).

Após as tabulações dos resultados dos questionários, foram feitas visitas nas duas empresas para entrevistas livres com os gerentes de RH e comparação com as informações geradas nos sociogramas, que foram, em seguida, apresentadas para os gestores de $\mathrm{RH}$ das duas empresas para verificação de coerência e consistência dos resultados.

As análises foram feitas com as medidas de densidade, centralidade, centralização, intermediação $e$ distância geodésica, baseadas em Borgatti, Everett e Freeman (2005), com uso do software Ucinet/Netdraw versão 6.232 .

Também foi usado o indicador E-I Index, baseado em Krackhardt e Stern (1988). Este índice é resultado da diferença entre laços internos e externos, dividido pelo total de laços: valores mais próximos de +1 indicam tendência de relacionamentos externos; já os valores mais próximos de -1 indica tendência a estabelecerem relacionamentos internos. Foi realizada a comparação entre o índice calculado e o esperado, que é obtido pelo número de relações possíveis tanto internamente aos grupos como externamente para aquela estrutura de grupos.

\section{As Redes da Estrutura Formal}

Os resultados mostram que as medidas de centralidade e de grau de intermediação foram elevadas (Quadro 1). Com isso foi possível perceber quem são os atores mais procurados (maior grau de centralidade) e quem são as pessoas que se aproximam das outras (grau de intermediação).

A Empresa 1 apresentou centralidade mais elevada $(9,6 \%)$ na rede de "trabalho" e na de "troca de ideias" $(12,7 \%)$. Isso significa que a estrutura formal influencia na centralidade. Já na Empresa 2 esses valores são bem mais baixos (trabalho $=4,7 \%$; troca de ideias $=4,0 \%$ ). Isso significa que na Empresa 2 há maior distribuição da comunicação e troca de ideias é mais comum. Ao contrário da Empresa 1, que apresenta comunicação mais centrada em poucas pessoas, assim como são poucas as pessoas que buscam trocar ideias sobre trabalho.

Nas duas redes as pessoas mais centrais estão em cargos gerenciais. A pessoa com maior centralidade é o gerente geral, o que indica que ele tem mais controle de informações e atua como ator central nos fluxos de trabalho, tal como sugerido por Toni e Nonino (2010).

A diferença está no nível de centralidade desses atores em suas empresas: o gerente geral da Empresa 1 apresentou nível de centralidade mais elevado, o que indica que gestores da Empresa 1 dependem mais do gerente geral para desenvolver suas atividades. Essa é uma evidência de que a centralidade em processos de trabalho e troca de informações funcionais é induzida pela estrutura formal da organização. No entanto, isso não significa que os relacionamentos informais de transferências de conhecimento e informações técnicas são condicionados pela estrutura formal. Há visivelmente uma influência, mas não uma condição.

As medidas de intermediação (Quadro 1) apresentam valores mais elevados para a Empresa 1 (na rede de trabalho $=8,2 \%$; troca de ideias $=10,5 \%$ ), do que para a Empresa 2 (rede de trabalho $=4,7 \%$ $e$ rede de troca de ideias $=5,1 \%$ ). Isso significa que os gestores da Empresa 1 precisam da intermediação para possibilitar conexão mais curta entre dois atores na rede. Na Empresa 1, o gerente geral se destaca como intermediador e apresentou também maior centralidade, favorecido pela estrutura. Logo, a linha de autoridade definida (MANDELLI, 2010) na Empresa 1 apresenta como vantagem a maior previsibilidade, eficiência e facilidade de controle.

$\mathrm{Na}$ Empresa 2, a maior intermediação foi dada ao gerente de uma filial. Isso indica que, na Empresa 2, a ausência de organograma permite maior flexibilidade de comunicação entre diversos atores, mesmo diante 
de sua dispersão espacial, que é um fator limitador desse comportamento. Esse fato possibilita que a autoridade do gerente seja oriunda do grupo e não da estrutura funcional. Neste caso, não se verificou a indução da estrutura formal nos relacionamentos informais.

\begin{tabular}{|c|c|c|c|c|c|}
\hline Indicadores & Empresa & TrabalHo & Pede Orientação & Fornece Orientação & Troca Ideia \\
\hline \multirow{2}{*}{ Centralidade } & Empresa 1 & $9,6 \%$ & $10,9 \%$ & $2,5 \%$ & $12,7 \%$ \\
\hline \multirow{2}{*}{ Grau de Intermediação } & Empresa 2 & $4.7 \%$ & $9,9 \%$ & $2,2 \%$ & $4,0 \%$ \\
\hline & Empresa 1 & $8,2 \%$ & $5,2 \%$ & $0,52 \%$ & $10,53 \%$ \\
\hline \multirow{2}{*}{$\begin{array}{c}\text { Média das Distâncias } \\
\text { Geodésicas }\end{array}$} & Empresa 2 & $4,7 \%$ & $11,8 \%$ & $1,3 \%$ & $5,1 \%$ \\
\hline
\end{tabular}

Quadro 1: Medidas por tipo de Rede das Empresas 1 e 2

Fonte: Dados da pesquisa de campo (2014)

Os dados confirmam que a Empresa 1 é mais estruturada pela hierarquia do que a Empresa 2. Os resultados das entrevistas confirmaram que a Empresa 1 é mais formal, já que tem seus processos registrados em manual que deve ser seguido com o acompanhamento do gerente geral. A Empresa 2, por não possuir um manual e nem dispor de organograma, apresenta, uma comunicação rápida, tal qual sugerido por Morand (1995), o que na visão de Flach e Antonello (2010), significa uma vantagem, por possibilitar ajuda mútua para aprendizagem entre os participantes da organização.

A força da estrutura formal sobre as relações de trabalho e de troca de ideias fica evidente a partir do E-I Index (Quadro 2). Nas duas redes os valores são negativos, mostrando os dois tipos de relacionamento circunscritos às áreas onde as tarefas são realizadas, mesmo havendo possibilidade de maior relação externa, visto que o índice esperado é positivo nos dois casos.
A influência da estrutura organizacional formal nos relacionamentos, como apresentado na rede de trabalho e de troca de ideias, foi concebida por Molina (2000) e por Cross, Borgatti e Parker (2002). Nestes trabalhos, a proximidade física ou mesmo a natureza da tarefa é percebida como favorável às interações entre as pessoas, pois são capazes de proporcionar relações pessoais diárias e resolução de problemas rotineiros em um mesmo contexto.

$\mathrm{Na}$ rede em que se "fornece orientação", as medidas encontradas para as duas empresas são similares (Quadro 2), o que significa que em ambas a orientação das equipes é realizada seguindo a mesma dinâmica, partindo dos gerentes para suas equipes $e$ são realizadas na maior parte do tempo internamente às lojas, como mostra o E-IIndex, que tem valores mais próximos de -1 (índice máximo de relacionamento interno). A rede da Empresa 1 atinge o valor de -0,667 e a Empresa 2 chega a -0,727 para valores ajustados.

\begin{tabular}{|c|c|c|c|c|c|}
\hline Medidas & INDICADORES & Trabalho & Solicita Orientação & Fornece ORientação & Troca IdeIAS \\
\hline \multirow{2}{*}{ Empresa 1} & E-I index Ajustado & -0.344 & -0.463 & -0.667 & -0.470 \\
\hline & E-I index Esperado & 0.357 & 0.236 & 0.239 & 0.307 \\
\hline \multirow{2}{*}{ Empresa 2} & E-I index Ajustado & -0.349 & 0.053 & -0.727 & -0.245 \\
\hline & E-I index Esperado & 0.542 & 0.476 & 0.718 & 0.605 \\
\hline
\end{tabular}

Quadro 2: Medidas do E-I Index das Empresas 1 e 2

Fonte: Dados da pesquisa de campo (2014) 
Os dados do E-I index permitem perceber as relações internas e externas dos integrantes de uma rede. No caso das redes estudadas na Empresa 2 há uma percepção de que existem pessoas competentes para ajudar em outras lojas (filiais ou matriz), além de seu local de trabalho. O pedido de orientação se dá tanto internamente, nas lojas onde atuam, como externamente (outras lojas), tendo em vista que o $E$-I Index foi positivo $(0,053)$, mostrando um equilíbrio entre as relações internas e externas, por estar próxima a zero.

$\mathrm{Na}$ Empresa 1, as relações para busca de orientação são, em sua maior parte, para outros da mesma loja, com um E-I Index negativo (-0,463). Portanto, as pessoas da Empresa 2 conseguem superar os obstáculos impostos pelo desenho organizacional para conseguir orientação; ao contrário dos que atuam na Empresa 1, que têm suas relações informais totalmente orientadas pela estrutura formal (Quadro 2).

Na Empresa 1, a decisão de maior formalização que resultou em maior importância para a hierarquia e comunicação de trabalho, ficou centrada no gerente geral, possivelmente, como defende Mandelli (2010), pela busca de conforto no gerenciamento. Já na Empresa 2, com menor formalização, a comunicação é mais distribuída na rede, o que pode ser resultado da busca por agilidade no processo decisório, como prevê Morand (1995).

\section{As Redes da Estrutura Informal}

A relação entre centralidade e intermediação não foi percebida na rede em que se pede orientação da forma como mostrado nas redes de trabalho e de troca de ideias (Quadro 3). Na rede em que se pede orientação, a centralidade apresenta valores próximos nas duas Empresas (Empresa $1=10,9 \%$; Empresa $2=9,9 \%$ ), enquanto os valores de intermediação são inversos nas duas empresas (Empresa $1=5,2 \%$; Empresa $2=11,8 \%$ ). O que mostra que as relações informais auxiliam a busca pelo conhecimento, mas a proximidade induzida pela estrutura formal é também determinante. Esse fato reflete que tanto a defesa de Garcia (2012) de que a rede informal determina como o trabalho é feito quanto a concepção de Nelson e Vasconcellos (2007) de que essas relações apresentam disfunções na implementação de estratégias.

Em ambiente com recursos dispersos (conhecimento), localização imprevisível e de difícil visualiza- ção, os participantes do ambiente organizacional se dispersam para buscar recursos, provocando queda na coesão do grupo. Pierce e White (1999) mostram que quando um recurso está concentrado, há necessidade da hierarquia para seu controle e distribuição, o que evita que a estrutura social seja quebrada. As respostas das duas empresas mostram que a hierarquia é mais exigida na Empresa 1 do que na Empresa 2, o que confirma a relação direta entre formas de disposição dos recursos (concentrado ou disperso) e hierarquia.

As duas empresas apresentam valores próximos para o nível de concentração do fluxo de pedido geral na rede, porém, a centralidade, que mede a influência de cada um dos atores, é mais distribuída, o que pode ser visto pela diferença entre valores do desvio padrão (Quadro 3).

\begin{tabular}{|l|c|c|c|c|}
\hline & \multicolumn{2}{|c|}{ EMPRESA1 } & \multicolumn{2}{c|}{ EMPRESA2 } \\
\hline & OutDegree & InDegree & OutDegree & InDegree \\
\hline Média & 7.053 & 7.053 & 4.793 & 4.793 \\
\hline $\begin{array}{l}\text { Desvio } \\
\text { Padrão }\end{array}$ & 7.679 & 10.613 & 5.732 & 5.238 \\
\hline Mínimo & 0.000 & 0.000 & 0.000 & 0.000 \\
\hline Máximo & 20.000 & 55.000 & 20.000 & 27.000 \\
\hline
\end{tabular}

Quadro 3: Dados de centralidade da rede "pede orientação" Fonte: Dados da pesquisa de campo (2014)

Na rede da Empresa 2 é maior o número de pessoas procuradas para dar orientação, confirmando que o conhecimento sobre melhores práticas de trabalho é mais distribuído. Essa possibilidade de ajuda mutua e de aprendizagem (LAMERTZ, 1999), segundo Flach e Antonello (2010), é de difícil percepção, mensuração e avaliação porque é predominantemente experimental.

Esperava-se que a estrutura hierarquizada $e$ dispersa das empresas pudesse contribuir para que os gerentes solicitassem orientação dentro de seus ambientes, como sustentam Cross et al. (2001). Porém, os resultados da Empresa 2 contrariaram as proposições de Cross et al. (2001) e de Cross, Nohria e Parker (2012). O que se percebeu foi que as equipes dessa empresa estão mais dispostas a buscar conhecimentos e informações fora das fronteiras físicas das unidades em que trabalham (outras lojas).

Os resultados mostram que os gestores buscam informações conhecimentos técnicos além das fronteiras da estrutura formal, usando a rede informal, porque 
é nela que acontece o que Lamertz (1999) trata como ajuda mútua e Flach e Antonello (2010) defendem como aprendizagem, pela integração de funcionários na realização de tarefas diárias.

$\mathrm{Na}$ Empresa 2, as pessoas percebem mais liberadade para pedir orientação além dos limites de suas lojas. Com essa busca elas mantêm o equilíbrio entre as relações internas e externas às lojas (E-I Index 0,053$)$, reforçando as concepções de Kleinbaum, Stuart e Tushman (2013) de que as interações revelam as preferências individuais e oportunidades seletivas.

Os exemplos de ações de melhorias sugeridas e implementadas pelos respondentes e seus colegas (referentes à venda, faturamento, receita, cuidados com clientes, controle de custos) mostram que as pessoas que estão em ambiente de maior troca entre lojas contribuem mais para a melhoria dos resultados. $\mathrm{O}$ que reforça a concepção de Gulati e Silvestri (2013) é que trocas como essas facilitam a realização de tarefas complexas.

Os respondentes da Empresa 1 apresentaram três respostas sobre melhorias sugeridas e implementadas: duas delas sobre organização do depósito $e$ aproveitamento de mercadorias para vendas ou para providências de devolução; a terceira sobre maior visibilidade na exposição de produtos. Os respondentes da Empresa 2 apresentaram 12 ações. Cinco ações foram referentes a vendas; outras três se referem a cuidados com clientes. Foi demonstrada ainda preocupação com o melhor gerenciamento dos custos e com a dispersão espacial dos negócios.

Esse aumento no número de ideais sugeridas $e$ implementadas acontece porque a estrutura de relações informais tem a capacidade de combinar recursos $e$ competências que são amplamente dispersos em toda a empresa. Isso confirma a concepção de Gulati e Silvestri (2013) sobre facilitação das tarefas induzidas pelas relações informais, o que reflete positivamente no desempenho organizacional quando se reduz os limites da estrutura formal (AKHTER; SIDDIQUE; MASUM, 2011) e passam a interagir com as relações formais orientadas pela estrutura hierárquica (SODA; ZAHEER, 2012).

\section{A Centralidade dos Gerentes}

Com exceção da rede em que se buscou saber "quem você orienta", na Empresa 1, a maior centralidade e intermediação é do gerente geral. Na Empresa 2 , o gerente geral é o ator central apenas na rede de trabalho. O maior destaque é para o gerente da maior regional (Belém), que é central nas redes em que se "pede orientação" e de "troca ideias" (Figura 1 e Figura 2).

O Gerente de RH da Empresa 2 relatou em entrevista que foi implementada uma mudança recente (menos de um ano) para reduzir a demanda sobre o gerente geral, com a criação do nível de gerentes regionais, dividindo as lojas em três áreas. Como não foi realizada pesquisa anterior, não é possível identificar o quanto houve de redução, mas é possivel perceber que o gerente geral (Figura 2) é central apenas na rede de trabalho e não há apenas um gerente que ocupe sozinho todas as outras posições de centralidades e intermediação, como se observa no gerente geral na Empresa 1 (Figura 1), que assume essa posição em função de seu controle sobre os processos.

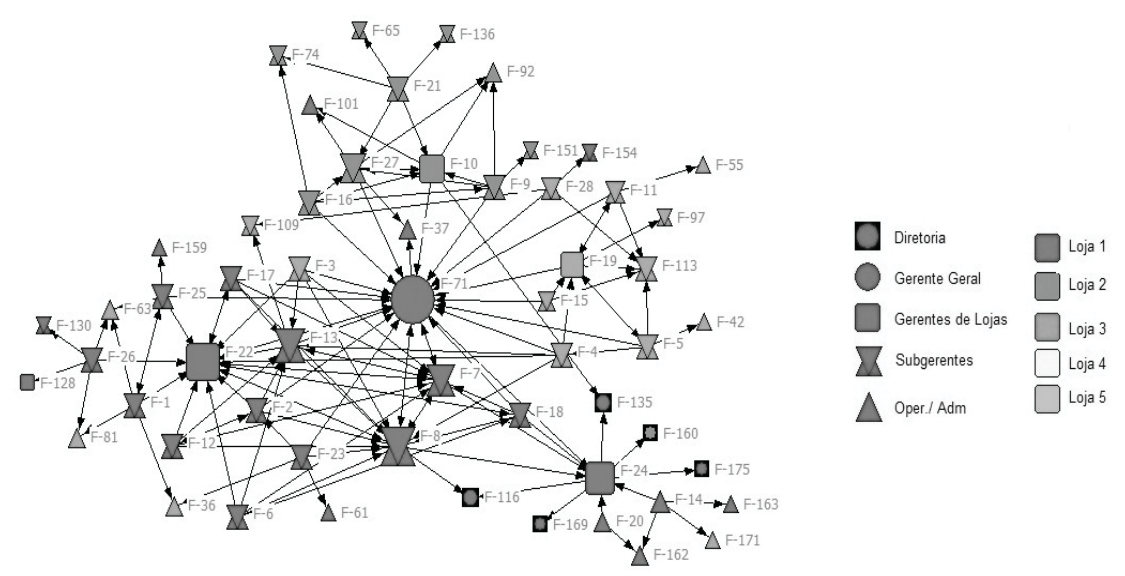

Figura 1: Rede "Pede Orientação" da Empresa 1

Fonte: Dados da pesquisa de campo (2014) 
As duas empresas apresentam diferentes cenários. A Empresa 1 possui maior nível de centralização que a Empresa 2. A centralização por um lado influencia no maior controle sobre os objetivos e uso dos recursos; por outro lado, subutiliza o conhecimento técnico $e$ tácito dos membros da equipe e a tomada de decisão pode ser mais demorada; enquanto a descentralização promove na equipe maior motivação, o que facilita na solução de problemas e nas necessidades de melhorias (CUNLIFFE, 2008).

Em nenhuma das redes das duas empresas a diretoria aparece centralizada ou fazendo intermediação (Figura 1 e Figura 2). Isso acontece, de acordo com Daft (2008), porque os níveis mais elevados das organizações estão envolvidos em estabelecer estratégias, metas. Já na concepção de Cross et al. (2001), o nível de direção assume atividades mais administrativas com pouco envolvimento na rotina, ficando menos acessíveis.
Quando se trata de relações no nível das gerências, a posição ocupada pela gerência de $\mathrm{RH}$ da Empresa 1 (ator F-24) é de intermediação. Nessa posição ele participa como terceira parte nas relações (Figura 1). O que o faz se posicionar, de acordo com Borgatti, Mehra e Brass (2009), como um ator com poder para conectar outros atores que não estão diretamente ligados e com isso se torna terceira parte nas relações.

Por outro lado, é evidente na rede "pede orientação" (Figura 2) a centralização do gerente de recursos humanos da Empesa 2 (ator S-21). A importância dessa posição para empresa é demonstrada pela prominência, medida pela centralidade de entrada. Isso acontece em função de haver demanda de outros gerentes pelo conhecimento sobre gestão de pessoas, além dos conhecimentos que promovam melhores práticas de trabalho, já que, segundo Cross, Borgatti e Parker (2002), o gerente capaz de usar a circulação desses recursos pode identificar oportunidades e melhor direcionar tais recursos.

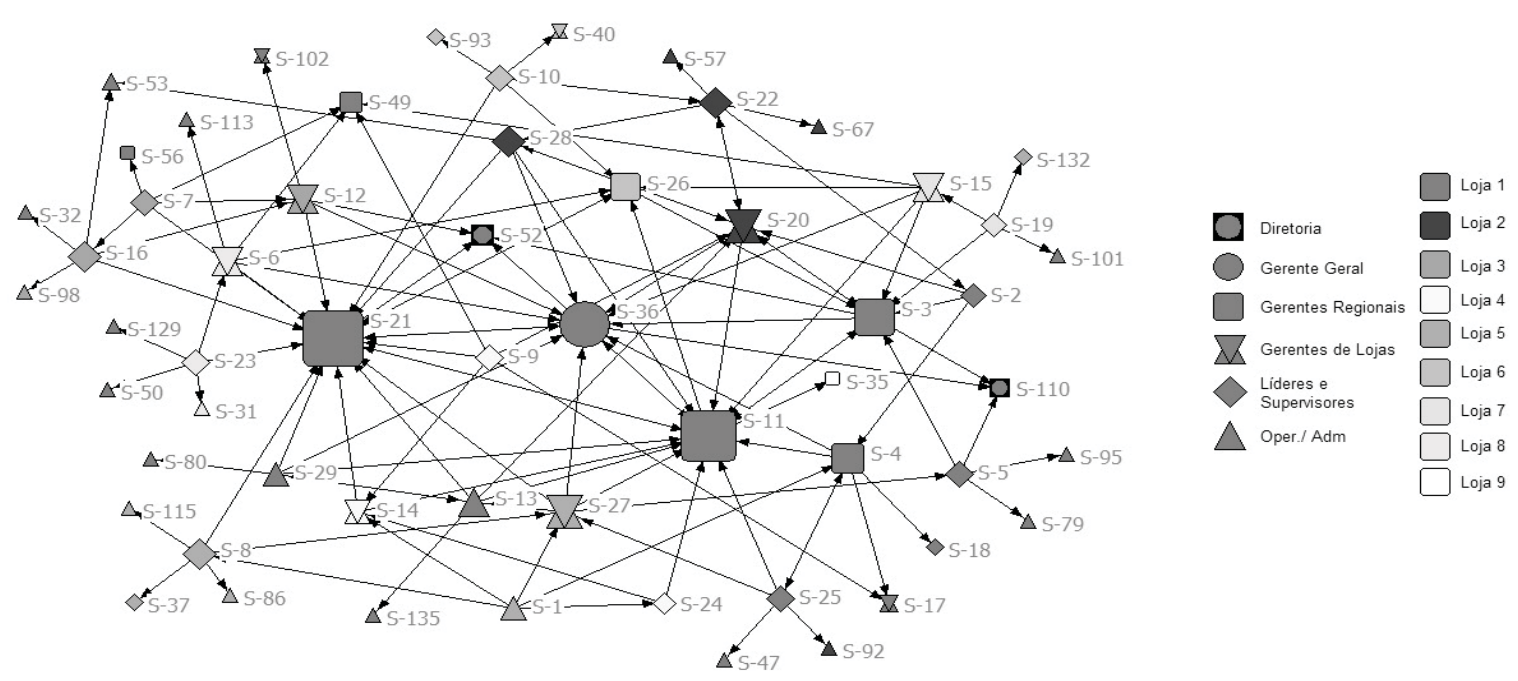

Figura 2: Rede Empresa 2 - Pede Orientação

Figura 2: Rede "Pede Orientação" da Empresa 2

Fonte: Dados da pesquisa de campo (2014)

A rede estruturada pela densidade das relações entre os níveis hierárquicos mostra que na Empresa 1 não foi identificada conexão direta entre o gerente geral e a diretoria (Figura 3). Isso acontece porque não houve indicação do gerente para a diretoria quando perguntado a quem ele solicita orientação. Por outro lado, os gerentes de lojas responderam que solicitam orientação para pessoas em nível de diretoria. A conexão com a diretoria está sendo realizada pelos gerentes de lojas que atuam como intermediadores com poderes de controle de informação, podendo agir como difusores dessas orientações ou restringindo sua difusão. 


\section{Empresa 1}

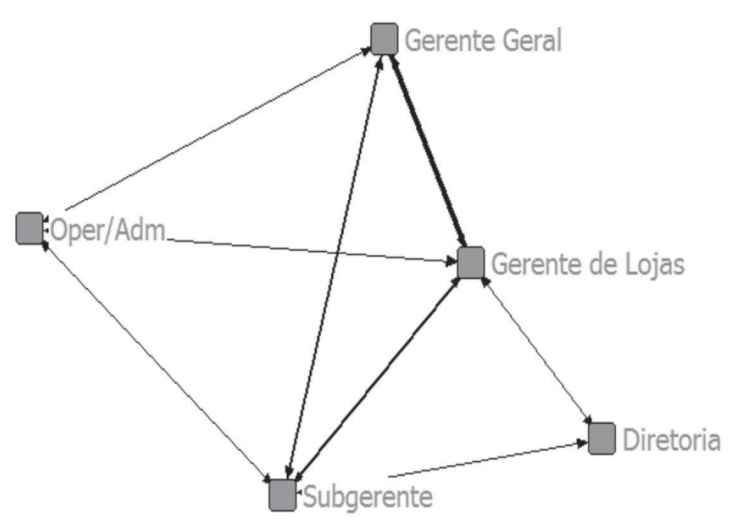

Figura 3: Rede "Pede Orientação" entre as Gerências

Fonte: Dados da pesquisa de campo (2014)

O que se percebe na Empresa 1 (Figura 3) é que o envolvimento do gerente geral com a rotina está associado a sua centralidade em todas as redes. Isso indica que sobra pouco tempo para discutir estratégias com a diretoria da empresa. O que pode está acontecendo é que a estrutura formal vem demandando desse gerente mais tempo no controle da equipe.

As espessuras das linhas do sociograma (Figura 3) entre as hierarquias mostram a intensidade das relações. Com isso é possível ver que as relações entre o gerente geral e seus gerentes de lojas são mais intensas que as demais na Empresa 1. Na Empresa 2, a maior intensidade é entre a diretoria e o gerente geral. Nessa empresa, o gerente geral exerce menor controle sobre a rotina, com apoio da estrutura formal que define os gerentes de lojas como donos do negócio.

\section{Conclusão}

A pesquisa revelou que nas duas empresas o conhecimento sobre os processos de trabalho difundidos nas redes informais da organização é capaz de gerar melhoria nos resultados. Esse conhecimento se propaga entre os gerentes e suas equipes, facilitado pela linha de hierarquia ou pela estrutura das redes informais.

As relações informais trazem mais agilidade e conseguem superar as barreiras impostas pela estrutura formal (desenho organizacional, hierarquia, dispersão espacial), porque permitem que conhecimentos e informações técnicas que estão dispersos cheguem a quem

\section{Empresa 2}

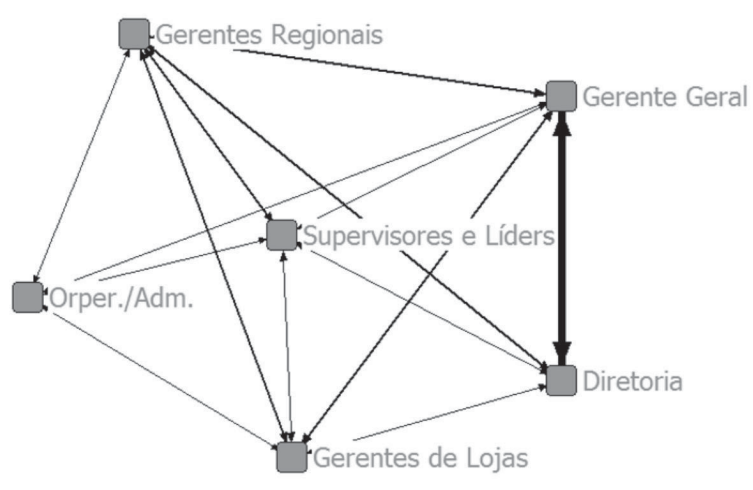

precise deles. Assim, a hierarquia funcional não é fonte exclusiva para promoção da difusão do conhecimento e informação na organização.

As evidências de um ambiente que permita a superação de barreiras impostas pela estrutura formal demonstram a importância das relações informais na melhoria dos processos de trabalho. Logo, mesmo o conhecimento técnico estando bem distribuído entre as funções hierárquicas, é necessário que haja condições para que ele seja acessado e utilizado para gerar melhorias no processo. Nesse caso, as relações informais representam mais uma oportunidade para a dispersão desse conhecimento.

A troca de conhecimento dependerá também de um contexto interno que permita a percepção de que os recursos estão dispersos e disponíveis a todos. Essa percepção diminui a centralização e proporciona ambiente colaborativo entre os participantes da organização.

A percepção de que o conhecimento está distribuído ao longo da rede (contexto de recursos) e que é possível sua aquisição, sem ter que passar pela estrutura hierárquica, facilita a obtenção de orientação $e$ conselhos para realização melhor o trabalho (melhores práticas). Essa percepção de ambiente favorável para troca de conhecimentos é dada pela estrutura formal ao configurar o contexto dos recursos.

Um ambiente de recursos concentrados aumenta a pressão hierárquica e restringe a troca de conhecimentos entre as diversas equipes. Já em um ambiente em que os recursos estão dispersos, as pessoas buscam 
por eles além da delimitação funcional, promovida pela estrutura formal, dando mais força às relações informais e reduzindo a força da hierarquia.

O departamento de recursos humanos se revelou como intermediador, quando o ambiente tem maior formalização dos processos de trabalho e maior respeito à hierarquia. Quando o ambiente tem hierarquia flexível e menor formalização dos processos, esse departamento se mostrou central.

Logo, o papel do departamento de RH é dado pelo contexto definido pela estrutura formal. No entanto, a pesquisa não conseguiu captar um fenômeno relevante que é a percepção de mudança no ambiente de acesso e circulação de recursos. Isso será possível a partir de uma pesquisa longitudinal.

\section{REFERÊNCIAS}

AKHTER, M.; SIDDIQUE, M. N.; MASUM, A. L. Analysis of social network and its effect on job satisfaction and employee performance. ASA University Review, [S.I.], v. 5, n. 1, p.195-207, 2011.

BORGATTI, S. P.; EVERETT, M. G.; FREEMAN, L.

C. Ucinet for Windows: software for social network analisys, MA: Analitic Tecnologies. 2005.

BORGATTI, Stephen P.; MOLINA, José Luis. Ethical and strategic issues in organizational social network analysis. The Journal of Applied Behavioral Science, [S.l.], v. 39, n. 3, p. 337-349, 2003.

CABRERA, L. C. de Q. Visões tradicionais e modernas de empresa, trabalho e pessoas. Manual de Gestão de Pessoas e Equipes: Estratégias e Tendências, [S.I.], v. 1, p. 47-58, 2002.

CROSS, Rob; PRUSAK, Laurence. The people who make organizations go-or stop. Harvard Business Review, [S.l.], v. 80, n. 6, p. 104-112, 2002.

CROSS, Rob.; BORGATTI, S. P.; PARKER, A. Making Invisible Work Visible: using social network analysis to support strategic collaboration. California Management Review, [S.I.], v. 44, n. 2, p. 25-46, 2002.

CUNLIFFE, Ann L. Organization theory. [S.l.]: Sage, 2008.
DAFT, Richard L. Teoria e projeto das organizações.

São Paulo: Cenage Learning, 2008.

DE TONI, Alberto F; NONINO, Fabio. The key roles in the informal organization: a network analysis perspective. The Learning Organization, [S.l.], v. 17, n. 1, p. 86-103, 2010.

DRUCKER, Peter. Administrando em tempos de grandes mudanças. São Paulo: Pioneira, 1995.

DRUCKER, Peter F. O melhor de Peter Drucker: a administração. São Paulo: Nobel, 2001.

DONALDSON, Lex. Teoria da contingência estrutural. In: CLEGG, Stewart R.; HARDY, Cynthia; NORD, Walter R. (Org.). Handbook de estudos organizacionais: modelos de análise e novas questões em estudos organizacionais. São Paulo: Atlas, 1999. v. 1, p. 105-133.

FLACH, Leonardo; ANTONELLO, Claudia Simone. A teoria sobre aprendizagem informal e suas implicações nas organizações. Gestão. Org, [S.l.], v. 8, n. 2, p. 193208, 2010.

GALBRAITH, Jay R. Organization design: An information processing view. Army Organizational Effectiveness Journal, [S.l.], v. 8, n. 1, p. 21-26, 1984.

GARCIA, Ignacio. Uma visão antropológica das redes sociais. Harvard Business Review Brasil, [S.I.], 12 jan. 2012.

GULATI, Ranjay; SILVESTRI, Luciana. Brokerage spaces: how informal networks transform formal structure in the pursuit of complex tasks. Academy of Management Proceedings, [S.l.], 2013.

HE, Jinyu; HUANG, Zhi. Board informal hierarchy and firm financial performance: Exploring a tacit structure guiding boardroom interactions. Academy of Management Journal, [S.l.], v. 54, n. 6, p. 1.119-1.139, 2011.

KLEINBAUM, Adam M.; STUART, Toby E.; TUSHMAN, Michael L. Discretion within the Constraints of Opportunity: Gender Homophily and Structure in a Formal Organization. Learning, [S.I.], 2013.

KRACKHARDT, David; STERN, Robert N. Informal networks and organizational crises: An experimental simulation. Social psychology quarterly, [S.l.], p. 123140, 1988. 
LAMERTZ, Kai. Exchange processes of interpersonal helping in the social structure of work groups. Academy of Management Proceedings. [S.1.]: Academy of Management, 1999. p. F1-F6.

MACDONALD, Ian; BURKE, Catherine; STEWART, Kalr. Systems leadership: creating positive organizations. Hampshire: Gower, 2006.

\section{MANDELLI, Pedro. Muito além da hierarquia:}

revolucione sua performance como gestor de pessoas. São Paulo: Gente, 2010.

MARSDEN, Richard; TOWNLEY, Barbara. A coruja de Minerva: reflexões sobre a teoria na prática. In: CLEGG, Stewart R.; HARDY, Cynthia; NORD, Walter R. (Org.). Handbook de estudos organizacionais: modelos de análise e novas questões em estudos organizacionais. São Paulo: Atlas, 2001. v. 1, v. 2, p. 31-56.

MINTZBERG, Henry. Criando organizações eficazes: estruturas em cinco configurações. São Paulo: Atlas, 1995.

MOLINA, José Luis. Lorganigrama informal a les organitzacions. Una aproximació des de l'anàlisi de xarxes socials. Revista Catalana de Sociologia, [S.l.], v. 11, p. 65-86, 2000.

MORAND, David A. The role of behavioral formality and informality in the enactment of bureaucratic versus organic organizations. Academy of Management Review, [S.I.], v. 20, n. 4, p. 831-872, Oct, 1995.

MORGAN, Gareth. Imagens da organização. São Paulo: Atlas, 2002.

MOSCOVICI, Fela. Renascença organizacional: a revalorização do homem frente à tecnologia para o sucesso da nova empresa. 10. ed. Rio de Janeiro: José Olympio, 2003.

NELSON, Reed. O uso da análise de redes sociais no estudo das estruturas organizacionais. Revista de Administração de Empresas, [S.l.],v. 24, n. 4, p. 150157, 1984.

NELSON, Reed Elliot; DE VASCONCELLOS, Eduardo P. G. O ambiente e o papo: Comparações internacionais e tipologia das redes verbais nas organizações. Rege -

Revista de Gestão, [S.l.], v. 14, número especial, p. 93-107, 2007.
OLIVEIRA, Djalma de Pinho Rebouças de. Estrutura organizacional: uma abordagem para resultados e competitividade. São Paulo: Atlas, 2006.

PIERCE, Barbara Decker; WHITE, Roderick E. The evolution of social structure: why biology matters. Academy of Management Review, [S.l.], v.24, n. 4, p.843-853, 1999.

PIERCE, Barbara Decker; WHITE, Roderick E. Resource context contestability and emergent social structure: an empirical investigation of an evolutionary theory. Journal of Organizational Behavior, [S.I.], v. 27, n. 2, p. 221239, 2006.

REQUENA SANTOS, Félix. El concepto de red social. Reis, [S.l.], p. 137-152, 1989.

REED, Michael. Teorização organizacional: um campo historicamente contestado. In: CLEGG, Stewart R.; HARDY, Cynthia; NORD, Walter R. (Org). Handbook de estudos organizacionais: modelos de análise e novas questões em estudos organizacionais. São Paulo: Atlas, 1999. v. 1, p. 61-98.

SODA, Giuseppe; ZAHEER, Akbar. A network perspective on organizational architecture: performance effects of the interplay of formal and informal organization. Strategic Management Journal, [S.l.], v. 33, n. 6, p. 751-771, 2012.

VERD, J. M.; et al. Aplicació de les xarxes socials a l'anàlisi de la formació invisible em l'empresa. Revista Catalana de Sociologia, [S.I.], v. 11, p. 87-104, 2000.

ZANCAN, Claudio; DA CRUZ FREIRE DOS SANTOS, Paulo; CAMPOS, Vanessa Oliveira. As contribuições teóricas da análise de redes sociais (ARS) aos estudos organizacionais. Revista Alcance, [S.l.], v. 19, n. 1, p. 62-82, 2012. 